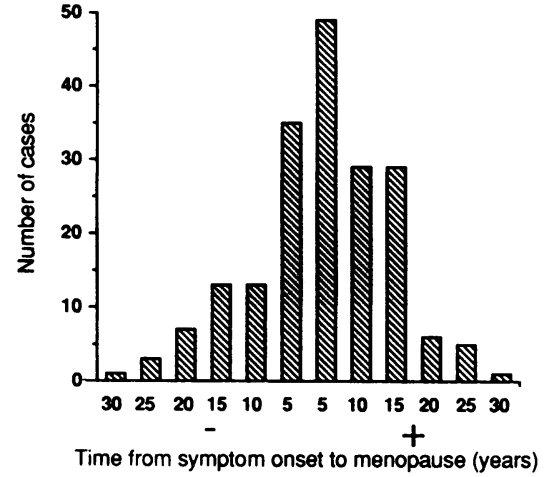

Figure 1 Relation between onset of rheumatoid arthritis and menopause in 191 postmenopausal women in a case-control study.

have arisen by chance, we tentatively suggested that other unknown genetic factors might have been responsible. We would be grateful for any other interpretations of the data. Unlike Dr McHugh we are unaware of the conclusive clinical evidence that pregnancy loss ameliorates existing disease, though this remains a possibility.

Dr McHugh suggests that the effect of the menopause should be given wider consideration owing to the age of onset in women. Dr McHugh's study showed a peak age of onset around the menopause, as did our larger casecontrol study (fig 1). There are a number of problems that have to be considered before a direct correlation can be postulated. Firstly, the age of onset distribution seen in hospital outpatient studies is not representative of all women with RA. This is because hospital case groups tend to contain those with more severe, longstanding disease, and patients developing RA at an older age will be underrepresented (fig 2). Population surveys are the only accurate way of determining ages of onset. In the United Kingdom these have confirmed that prevalence does indeed increase at the menopause, but remains at this level thereafter. ${ }^{1}$ Another study of incidence related to age at the Mayo clinic found that this increased steadily in women and men. ${ }^{2}$ If the menopause were a major factor one might expect differences in prior age of menopause or incidence of artificial menopause and these have not been found in studies. ${ }^{3-5}$ As well as the mentioned bias due to recall of disease onset, it should be remembered that surveys have shown that up to $50 \%$ of women with

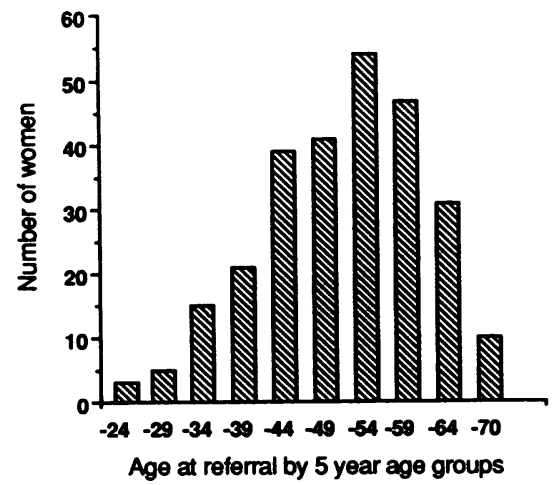

Figure 2 Distribution of age at onset of women with rheumatoid arthritis from a case-control study. (Source: Spector TD. Hormonal and reproductive factors in the aetiology of $R A . M D$ thesis, University of London, 1989.) menopausal symptoms have joint pain, ${ }^{6}$ and this is likely to be confused with early RA.

A number of studies have looked at hormonal status of women with RA, and, unfortunately, no consistent abnormalities have been detected. ${ }^{7}$ We are just completing a prospective study examining the hypothesis that hormone replacement therapy (HRT) is protective against the development of RA. The data on the possible protective effects of HRT are patchy and contradictory at present and suffer from many of the methodological problems outlined above. Although hormonal change at the menopause may be a factor in RA, current evidence suggests that prior pregnancy and oral contraceptive use at an earlier age may be of more importance. ${ }^{8}$

TIM D SPECTOR ALAN J SILMAN Departments of Environmental and Preventive Medicine and Rherumatology Medical College of St Bartholomew's Hospital London ECIM $6 B Q$ $A R C$ Epidemiology Unit Manchester MI3 9PT
M Epidemiology Unit

1 Lawrence J S. Rheumatism in populations. London: Heinemann, 1977.

2 Linos A, Worthington J W, O'Fallon W M Kurland L T. The epidemiology of rheumatoid arthritis in Rochester, Minnesota: a study of its arthritis in Rochester, Minnesota: a study of its incidence, prevalence and
Epidemiol 1980; 111: 87-98.

3 Vandenbroucke J P, Witteman J C, Valkenburg $\mathrm{H} \mathrm{A}$, et al. Noncontraceptive hormones and rheumatoid arthritis in perimenopausal and postmenopausal women. $\mathscr{J} A M A$ 1986; 255: $1299-303$.

4 Short C L, Bauer W, Reynolds W E. Rheumatoid arthritis. Cambridge, Mass: Harvard University Press, 1957.

5 Spector T D, Brown G C, Silman A J. Increased rates of previous hysterectomy and gynaecological operations in women with osteoarthritis. Br Med $\mathcal{F}$ 1988; 297: 899-900.

6 Neugarten B L, Kraines R J. "Menopausal symptoms" in women of various ages. Psychosom Med 1965; 27: 266-73.

7 Spector T D. Sex hormone measurements in RA. Br F Rheumatol 1989; 28 (suppl 1): 62-9.

8 Spector T D, Roman E, Silman A J. The pill, parity and rheumatoid arthritis. Arthritis Rheum (in press).

\section{Sternoclavicular erosions in polymyalgia} rheumatica

Sir: We read with interest the article by Kyle et al about the rarity of synovitis in polymyalgia rheumatica. ${ }^{1}$ In their work sternoclavicular erosions were seen in only $2 / 19$ of the tomograms obtained. Our experience contradicts these results. ${ }^{2}$

From 1984 to 1987 tomography of sternoclavicular joints was carried out in 21 patients (12 female, nine male) with active untreated polymyalgia rheumatica, seven of whom also had giant cell arteritis. Their mean age was 68.8 years. All had a negative Rose-Waaler test. In addition, control tomograms were obtained from 18 volunteers (mean age 69.2 years) who had no clinical evidence of inflammatory arthropathy. The films were all examined by one consultant radiologist and two rheumatologists with no knowledge of clinical data.

The incidence of erosions was significantly higher $(p<0.05)$ in patients with polymyalgia rheumatica $(9 / 21)$ than in control subjects (1/18). Erosions were found more often in patients who had had symptoms for more than six months. There was no correlation between local pain elicited by pressure and the presence of articular erosions.
Our findings support the existence of an erosive arthropathy in polymyalgia rheumatica and are in agreement with the study of Paice $e t$ al previously published in the Annals. ${ }^{3}$

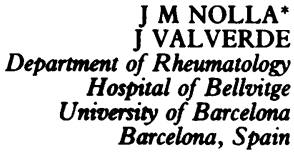

*Correspondence to: Dr J M Nolla, Department of Rheumatology (10-2), Hospital of Bellvitge, 08907 L'Hospitalet de Llobregat, Barcelona, Spain.

I Kyle V, Tudor J, Wraight E P, Gresham G A, Hazleman B L. Rarity of synovitis in polymyalgia rheumatica. Ann Rheum Dis 1990; 49: myalgia

2 Nolla J M, Valverde J, Andia E, et al. Erosiones esternoclaviculares en la polimialgia reumática. Revista Espanola de Reumatologia 1989; 16: 41-3.

3 Paice E W, Wright F W, Hill G S. Sternoclavicular erosions in polymyalgia rheumatica.
Ann Rheum Dis 1983; 42: 379-83.

Immunological indices of patients with rheumatoid arthritis after methylprednisolone pulse therapy

Sir: In a previous letter to the Annals we reported the favourable clinical results obtained by high dose intravenous methylprednisolone treatment in active rheumatoid arthritis. ${ }^{1} \mathrm{We}$ now present the changes in the immunological indices for these same patients.

The discovery of monoclonal antibodies has enabled the determination of different lymphocyte subgroups. ${ }^{2-9} \mathrm{We}$ investigated the cellular and humoral immune response of 10 patients with active, classical rheumatoid arthritis. The total lymphocyte count (OKT3), the inducer/helper (OKT4) and suppressor/ cytotoxic (OKT8) subgroups were determined with Orthomune monoclonal antibodies by the immunoperoxidase method according to Erber. ${ }^{10}$ Concentrations of $\mathrm{C} 3, \mathrm{C} 4$, and the immunoglobulins were measured by Mancini's radial immunodiffusion. Determination of immune complexes was by polyethylene glycol precipitation and cross electrophoresis. Blood samples for determinations were taken before infusion and after $2,6,24$, and 48 hours.

Before infusion we found a high level of helper cells: mean $69 \cdot 1 \%$ (range $59-78 \%$ ), absolute number $1921 / \mu \mathrm{l}(1120-3321)$, and a low concentration of suppressor cells: mean $25 \cdot 8 \%(21-34 \%)$, absolute number $808 / \mu$ (352-1700), in agreement with published data. ${ }^{246711-15}$ The so-called immunoregulatory ratio-the helper/suppressor quotient-was increased to 2.65 (normal 1.55), as found by others. ${ }^{2-4611}$ This disequilibrium of the immune response was favourably influenced by high dose intravenous methylprednisolone pulse therapy, which decreased the centile proportion: mean $45 \cdot 3 \%(24-63 \%)$ and the absolute number: mean $418 / \mu l(135-715)$ of T4 cells, thus leading to a normal helper/ suppressor ratio. According to Bertouch the cause of selective diminution of helper cells is the remigration of the circulating lymphocytes into the peripheral lymph nodes and bone marrow. 2 16 17 As the lymphopenia was only transitory and the excretion of uric acid did not rise after the pulse treatment the decrease of cell numbers is probably due to a change in the division of circulating cells and not to cell lysis. ${ }^{18}$ 
We noted a marked diminution of absolute B cell numbers, as Silverman also found. ${ }^{19}$ Before infusion the mean absolute $B$ cell number was 758/ $\mu \mathrm{l}(320-1200)$ and after six hours $238 / \mu \mathrm{l}(65-494)$. This is clinically important as it temporarily interrupts antibody production. The immunomodulation caused by the megadose intravenous steroid dose was only transitory and the $T$ subpopulation and $B$ cell level returned to their initial levels 24 hours after the infusions. Because methylprednisolone is rapidly excreted (half life: three hours) $99 \%$ of the dose is eliminated in one day, and thus its effect diminishes rapidly. ${ }^{18}$ Several authors have noted a significant decrease in the IgG, IgA, C3, C4, and immune complex concentrations after methylprednisolone pulse therapy.8 ${ }^{2021}$ These indices of humoral immune response were normal in our patients: (IgG 12.5 (SD 3.633) -11.6 (2.986) g/l; IgA 2.3 (1.4)-2.2 (1.1) g/l; IgM $1.09(0.48)-1.17 \quad(0.32)$ g/l; C3 0.93 $(0.12)-1.09(0.23) \mathrm{g} / 1 ; \mathrm{C} 4 \quad 0.27(0.13)-0.24$ $(0 \cdot 1) \mathrm{g} / \mathrm{l})$ and were unchanged during the methylprednisolone pulse therapy.

The immune complex concentration was normal before the infusion: mean $210.6 \mathrm{ng} / \mathrm{m}$ (124-303), and Clq binding was negative in all patients. These values were not influenced by the infusions.

Thus, in summary, despite the brief immunomodulation the megadose steroid treatment is of therapeutic importance in the treatment of active rheumatoid arthritis resistant to other drugs. Decreased suppressor cell activity and consequently high $\mathrm{T} 4 / \mathrm{T} 8$ ratio are usually found in the active clinical state, ${ }^{2} 31122$ in contrast with the normal concentrations present in patients in remission. Rapid correction of the high helper/suppressor ratio may favourably influence the immunological disequilibrium and so perhaps prolong clinical remission.

\section{N KAPISINSZKY Baranya megyei Tanács Gyóg fürdö Kórhaza 7815 Harkany Zsigmondy setany Hungary}

1 Kapisinszky N, Keszthelyi B. High dose intravenous methylprednisolone pulse therapy in patients with rheumatoid arthritis. Ann Rheum Dis 1990; 49: 567-8.

2 Bertouch J V, Roberts-Thomson P J, Brooks $P$ M, Bradley J. Lymphocyte subsets and inflammatory indices in synovial fluid and blood of patients with rheumatoid arthritis. $\mathcal{J}$ Rheumatol 1984; 11: 754-9.

3 Duke O, Panayi G S, Janossy G, Poulter L W, Tidman N. Analysis of $T$ cell subsets in the peripheral blood and synovial fluid of patients with rheumatoid arthritis by means of monowith rheumatoid arthritis by means of monoclonal antib

4 Emery P, Gentry K C, Mackay I R, Muirden K D, Rowley M. Deficiency of the suppressor inducer subsets of T lymphocytes in rheumatoid arthritis. Arthritis Rherom 1987; 30: 849-56.

5 Førre $\varnothing$, Thoen J, Dobloug J H, et al. Detection of $T$-lymphocyte subpopulation in the peripheral blood and the synovium of patients with rheumatoid arthritis and juvenile chronic arthritis using monoclonal antibodies. Scand $f$ Immenol 1982; 15: 221-6.

6 Luyten F, Suykens S, Veys E M, et al. Periphera blood $T$ lymphocyte subpopulations determined by monoclonal antibodies in active rheumatoid arthritis. $f$ Rheumatol 1986; 13: $864-9$.

7 Raeman F, De Cock W, De Beukelaar T, De Cree J, Verhaegen J. Enumeration of T lymphocytes and $T$ lymphocyte subsets in autoimmune disease using monoclonal antibodies. Clin Exp Immunol 1981; 45: 475-9.

8 Smith M D, Ahern M H, Roberts-Thomson P J. Pulse steroid therapy in rheumatoid arthritis: Can equivalent doses of oral prednisolone give Can equivalent doses of oral prednisolone give
similar clinical results to intravenous methylprednisolone? Ann Rhewm Dis 1988; 47: 28-33.
9 Verbruggen G, Steenkiste $M$ V, Delange F. Influence of low dose corticosteroids on the $T$ cell subsets in peripheral blood. Arthritis Rheum 1982; 25 (suppl): 69.

10 Erber $W$ N, Pinching A J, Mason D Y. Immunocytochemical detection of $\mathrm{T}$ and $\mathrm{B}$ cell populations in routine blood smears. Lancet 1984; i: 1042-5.

11 Egeland T, Lea T, Mellbye $O \mathrm{~J}$. T cell immunoregulatory functions in rheumatoid arthritis regulatory functions in rheumatoid arthritis

12 Hermanns P, Verbruggen G, Veys E M. Deter mination of $T$ cell subpopulations with monoclonal antibodies in the synovial fluid of patients with rheumatoid arthritis. Arthritis Rhewon 1982; 25 (suppl): 70

13 Hermanns P, Verbruggen C, Veys E $M$ Vansteenkiste $M$, Delanghe J, Mielants $N$. Influence of low dose corticosteroid administration on the lymphocyte subpopulations. f Rhewnatol 1982; 9: 648 .

14 Saldate E M C, Rivero S J, Alarcón-Segovia D. Determination of T lymphocyte subpopulations with monoclonal antibodies. Variations in the different connective tissue diseases. Arthritis Rhewon 1982; 25 (suppl): 69.

15 Veys E M, Hermanns $P$, Schindler J, et al. Evaluation of T cell subsets with monoclonal antibodies in patients with rheumatoid arthritis. f Rherumatol 1982; 9: 25-9.

16 Bertouch J V, Roberts-Thomson P J, Smith M D, Woodruff T G, Brooks P M, Bradley J. Methylprednisolone infusion therapy in rheumatoid arthritis patients. Arthritis Rheum 1986; 29: 32-9.

17 Bertouch J V, Roberts-Thomson P J, Bradley J. Diurnal variation of lymphocyte subsets identified by monoclonal antibodies. Br Med F 1983; 286: 1171-2.

18 Pentikainen P J. Pharmacological aspects of corticosteroid pulse therapy. Scand $\mathcal{F}$ R hewmatol [Suppl] 1984; 54: 6-10.

19 Silverman E D, Myones B L, Miller J J. Lymphocyte subpopulation alterations induced by intravenous megadose pulse methylprednisolone. F Rhewmatol 1984; 11: 287-90.

20 Forster P J G, Grindulis K A, Neumann V Hubbal S, McConkey B. High-dose intravenou methylprednisolone in rheumatoid arthritis. Ann Rhewn Dis 1982; 41: 444-6.

21 Kurki P. Influence of steroid pulse therapy on the immune system. Scand $\mathcal{F}$ Rheumatol [S uppl] 1984; 54: 13-16.

22 Faure G, Kahn M F, Bach M A, Bach J F. T-cel subsets in the blood of rheumatoid arthritis 1982; 25: 1507-9.

\section{Response criteria for slow acting} antirheumatic drugs

Sir: I applaud Scott and his colleagues for putting one of the recommendations of the consensus meeting ${ }^{1}$ into practice by attempting to derive simple criteria to define response to second line treatment. ${ }^{2}$ The approach used does have some problems, however, and I would like to offer some possible modifications for consideration.

To select parameters on the basis of percentage change after treatment with respect to baseline results is misleading. The norma results for articular index, pain, and morning stiffness are all zero. A normal erythrocyte sedimentation rate (ESR) tends towards $<10$ $\mathrm{mm} / \mathrm{h}$ but is dependent on age and sex. The other indices investigated all have finite normal ranges and these need to be taken into

Table 1 Application of Scott's criteria ${ }^{2}$ to two patients

\begin{tabular}{|c|c|c|c|c|c|c|}
\hline & \multicolumn{3}{|c|}{ Patient $A$} & \multicolumn{3}{|c|}{ Patient B } \\
\hline & Before & After & Response & Before & After & Response \\
\hline $\begin{array}{l}\text { ESR* }(\mathrm{mm} / \mathrm{h}) \\
\text { Pain }(\mathrm{cm}) \\
\text { Stiffess (min) } \\
\text { Articular index }\end{array}$ & $\begin{array}{r}65 \\
6 \\
120 \\
18\end{array}$ & $\begin{array}{r}35 \\
4 \\
30 \\
6\end{array}$ & $\begin{array}{l}\mathbf{0} \\
\mathbf{0} \\
\mathbf{0} \\
\mathbf{0}\end{array}$ & $\begin{array}{r}35 \\
4 \\
40 \\
8\end{array}$ & $\begin{array}{r}25 \\
2 \\
10 \\
11\end{array}$ & $\begin{array}{l}1 \\
1 \\
1 \\
0\end{array}$ \\
\hline Overall response & & & 0 & & & 3 \\
\hline
\end{tabular}

${ }^{*} E S R=$ erythrocyte sedimentation rate.

account in calculating the percentage change. For example, a measurement with an upper limit of normal of 100 units might be said to have improved $100 \%$ if a result of 120 falls to $\leqslant 100$-that is, to normal, but by Scott's method it has only improved by $20 \%$. It is apparent that had $\mathrm{C}$ reactive protein been included it would have shown a high percentage improvement, whereas plasma viscosity would have faired badly. Despite this, however, the measures selected are similar to those identified by more sophisticated statistical methods ${ }^{34}$ and would also be the choice based on common sense, reflecting several aspects of active rheumatoid disease which might be expected to improve with successful second line treatment.

If we apply the Scott criteria to two patients $A$ and $B$ we can see a particular problem with the approach (table 1). The response scores for the two patients are clearly misleading, and this has resulted primarily from the fact that the response criteria do not take into account the initial disease activity. After treatment patient $\mathbf{A}$ has fewer tender joints than patient $B$ and has had a greater reduction in ESR and duration of morning stiffness, but patient B has the greater response score.

As second line treatment does not 'cure' rheumatoid arthritis a positive response to treatment will fall somewhere between the presenting disease state and complete relief of all signs and symptoms. It is therefore more reasonable to have several grades of response or even a scale of response, but it needs to take the initial disease state into consideration. Use of the same simple measures used by Scott in a scale of response also has its problems. If we assume that the four variables are all equally important then we need to know what particular ESR, pain, stiffness, and articular index results equate with one another so that standardised results can be determined and readily combined. For example, let us suppose that clinical data suggest the approximate equivalents shown in table 2. (These are based on actual data generated in Leeds but need to be refined.) If we apply these criteria to patients $A$ and $B$ in table 1 we see the scores are:

$\begin{array}{lll}\text { Patient A } & \begin{array}{l}\text { before: } \\ \text { after: } \\ \text { response: }\end{array} & \begin{array}{l}5+6+3+5=19 \\ 2+4+1+2=9 \\ 19-9=10\end{array} \\ \text { Patient B } & \begin{array}{l}\text { before: } \\ \text { after: } \\ \text { response: }\end{array} & \begin{array}{l}2+4+1+2=9 \\ 1+2+1+3=7\end{array} \\ & 9-7=2\end{array}$

The response achieved in patient $B$ is now seen in a more sensible light. There is some response, but because the score before treatment was the same as for patient $A$ after treatment it is perhaps not surprising that the gain for patient $B$ is less. This approach provides three pieces of information about each patient-the initial and final disease activity, and the difference (the response). These three, derived from a simple scale of response, provide more useful information response, provide more useful information
and, with refinement, might be of practical 